\title{
Effect of tapered angles in an artery on distribution of blood flow pressure with gravity considered*
}

\author{
Wenying $\mathrm{Mu}^{1}$, Shanguang $\mathrm{Chen}^{2}$, Changsheng $\mathrm{Ma}^{1}$, Jianzeng Dong ${ }^{1}$ \\ ${ }^{1}$ Department of Cardiology, Beijing Anzhen Hospital, Capital Medical University, Beijing, China \\ ${ }^{2}$ National Key Laboratory of Human Factors Engineering, China Astronaut Research and Training Center, Beijing, China \\ Email: happy_mwy@163.com, paper_c@163.com
}

Received 10 October 2013; revised 15 November 2013; accepted 29 November 2013

Copyright (C) 2013 Wenying Mu et al. This is an open access article distributed under the Creative Commons Attribution License, which permits unrestricted use, distribution, and reproduction in any medium, provided the original work is properly cited.

\begin{abstract}
The tapered angles of an artery significantly influence the local hemodynamics. However, as gravity is considered, little is known about the effect of tapered angles on the hemodynamics. In this study, we explored whether the effect of tapered angles on the distribution of blood flow pressure (DBFP) differed with gravity considered or not. Numerical simulations of the DBFP in a single vessel were performed based on such tapered angles as $0^{\circ}, 0.5^{\circ}$ and $1^{\circ}$. In the model used for simulation, gravity was introduced as a body force. We obtained the following simulations: i) The larger the tapered angles were, the better distributed the blood flow pressure; ii) The tapered effect was an important factor leading to nonlinearity in blood flow pressure; iii) Gravity affected DBFP coupling with the tapered angles, yet independently influenced the dimension of the DBFP. At the same time, the effective intensity of gravity decreased with the increase of tapered angles.
\end{abstract}

Keywords: Tapered Angles; Distribution of Blood Flow Pressure (DBFP); Gravity; Numerical Simulation

\section{INTRODUCTION}

As human enters into space and exposes to microgravity, a series of adaptations, such as blood redistribution, occur [1]. The alteration is simulated by tilt table test on the ground, which is adopted widely during the selection and training of astronauts [2-4]. The essential difference between the simulation test and real situation in space lies in the change of gravity.

Therefore, it is the first step to determine the effect of gravity on the hemodynamics.

The distribution of blood flow pressure characterizes

*There are no conflicts of interest for the authors of this study. the cardiovascular function of human body and represents the space state of blood flow. The arterial tapered angles affected greatly the hemodynamics of the arterial system in mammals [5]. For human arterial system, tapered angles at different levels are different and have an important impact on the hemodynamics. So in many cases, the tapered angle may be an important factor leading to cardiovascular dysfunction or diseases $[6,7]$.

In recent years, many researchers have investigated the tapered angles in the clinical study of human arterial blood flow. Some of them have divided the stenosed arteries into three types of non-tapered angle, divergent tapered angle and convergent tapered angle to explore the relationship between the arterial stenosis and tapered angles. Among these studies, the effect of tapered angles on hemodynamics is an important part discussed [6,8-10]. In addition, some researchers have concluded that the tapered angles in different arterial sections influence the fatty streaks and injury distribution of the artery on the basis of the measurement of the medical images, and have suggested that the tapered angle is an important factor leading to the development of atherosclerosis [11]. In the above study, gravity was not considered as a contributor.

In contrast, in the aerospace field, the variation of gravity is a key issue that needs to be taken into account. However, the existed mathematical models in cardiovascular hemodynamics are mainly lumped parameter models, which are founded on the thought of analog circuit. So, gravity could only be considered in scalar quantity, while the effect of tapered angle could not be included at all in the lumped-parameter model $[12,13]$. At present, considering as many factors as possible to obtain the precise results is bringing more and more attention. The distribution of blood flow pressure (DBFP) can quantify the temporal and spatial information of cardiovascular system more accurately. Yet up to now, under different tapered angles and with gravity involved as a 
body force, DBFP has been studied inadequately.

In this study, by the aid of the postural model in which gravity was considered as a body force [14], DBFP in a single vessel was simulated numerically under different tapered angles with or without gravity considered as a contributor. Then it was made clear if the effect of tapered angles on DBFP depended on gravity or not.

\section{METHODS}

\subsection{Mathematical Model}

The mathematical model with posture was adopted [14]. In this model, gravity was introduced as body force. Therefore, the native of gravity as a vector was reflected.

Equation of Continuity

$$
\nabla \cdot(A \overrightarrow{\boldsymbol{U}})=0
$$

Equation of Motion

$$
\rho(\overline{\boldsymbol{U}} \cdot \nabla) \overrightarrow{\boldsymbol{U}}=\rho \overline{\boldsymbol{F}}_{b}+\nabla \cdot \overline{\overline{\boldsymbol{P}}}
$$

where $\rho(\overrightarrow{\boldsymbol{U}} \cdot \nabla) \overrightarrow{\boldsymbol{U}}$ is the inertial force, $\nabla \cdot \overline{\overline{\boldsymbol{P}}}$ is the surface force, $\rho \overrightarrow{\boldsymbol{F}}_{b}$ is the body force, which was identified as the key term to reflect the postural change, $\rho$ represents the blood density, $\overline{\boldsymbol{F}}_{b}$ represents the body force per unit mass of blood, $\overline{\overline{\boldsymbol{P}}}$ represents the second order stress tensor of the blood pressure, $\overrightarrow{\boldsymbol{U}}$ represents the blood velocity, and $A$ represents the cross-sectional area of the vessel.

\subsection{Finite Element Model}

The carotid artery was taken as a computational case. The carotid artery is one of the systemic arteries. The blood flow in it is assumed to be homogeneous, incompressible, viscous and Newtonian fluid $[15,16]$, the vessel wall can be assumed to be rigid $[17,18]$. The geometric model of the single vessel is shown in Figure 1.

The geometric dimensions of the vessel [19] and the material parameters of blood $[15,16]$ are listed in Table1.

The value of $\mathrm{D} 2$ was determined by the tapered angle $\alpha$, and $\alpha$ was among $\left[0^{\circ}, 1^{\circ}\right], h$ represents the wall thickness of the vessel. The inlet-outlet pressures were set to be constant respectively, and the pressure difference was set $199.98 \mathrm{~Pa}(1.5 \mathrm{mmHg})$. The solid-wall boundary condition was applied to the surrounding of the vessel wall. The tool used in numerical computation was ADINA (Automatic Dynamic Incremental Nonlinear Analysis, ADINA R\&D, Inc., Watertown, MA, USA), a comercial software package for finite element analysis. Some researchers before $[20,21]$ had used the software in biological system. Owing to the consideration of the effect of gravity, the model was meshed by three-dimensional fluid element. Then the finite element model was built up (shown in Figure 2).

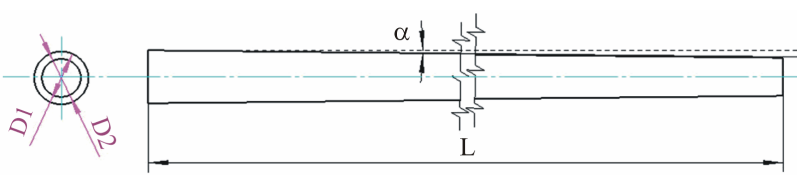

Figure 1. Geometric model of the single vessel.

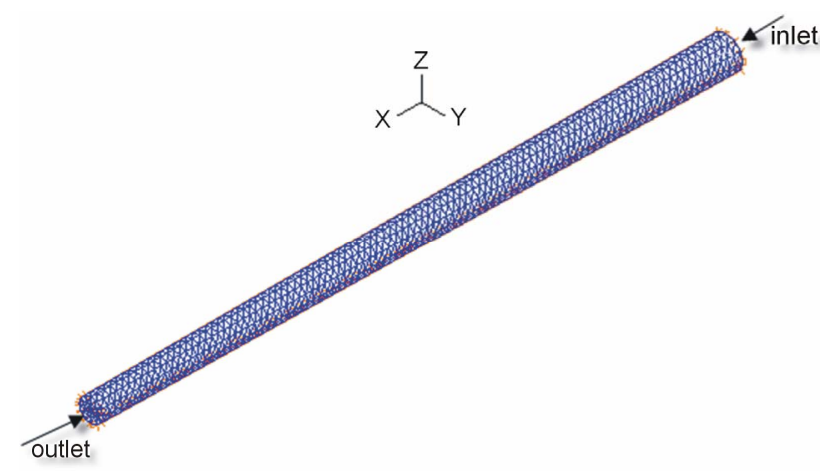

Figure 2. Finite element model of a single vessel.

Table 1. Geometric and material parameters of the single vessel.

\begin{tabular}{cccccc}
\hline $\begin{array}{c}L \\
(\mathrm{~mm})\end{array}$ & $\begin{array}{c}D_{1} \\
(\mathrm{~mm})\end{array}$ & $\begin{array}{c}h \\
(\mathrm{~mm})\end{array}$ & $\begin{array}{c}\alpha \\
\left({ }^{\circ}\right)\end{array}$ & $\begin{array}{c}\mu \\
(\mathrm{Pa} \cdot \mathrm{s})\end{array}$ & $\begin{array}{c}\rho \\
\left(\mathrm{kg} \cdot \mathrm{m}^{-3}\right)\end{array}$ \\
\hline 145.00 & 10.74 & 0.35 & {$\left[0^{\circ}, 1^{\circ}\right]$} & 0.0035 & 1050.00 \\
\hline
\end{tabular}

(The viscosity $\mu$ and the density $\rho$ equal to the normal values of human blood at $37^{\circ} \mathrm{C}$ ).

For the eleven tapered angles among $\left[0^{\circ}, 1^{\circ}\right]$, with gravity considered or not, the corresponding finite element models were presented respectively. Then by comparing the typical numerical results at $0^{\circ}, 0.5^{\circ}$ and $1^{\circ}$ tapered angles, it was found out whether there existed some difference in the effect of tapered angles on the blood flow pressure distribution with gravity considered or not.

\section{RESULTS AND DISCUSSIONS}

With gravity considered or not, in fluid-only model, as tapered angle $\alpha$ was equal to $0^{\circ}, 0.5^{\circ}, 1^{\circ}$ respectively, the contour charts of the blood flow pressure distribution in the transverse and longitudinal sections, were shown respectively in Figures 3(a), (b) and 4.

In the contour chart of blood flow pressure distribution in longitudinal section (Figures 3a(i)-3a(iii)), with gravity considered $(G \neq 0)$ and taking $0^{\circ}$ tapered angle as the reference one (namely cylindrical vessel commonly adopted), the pressure distribution of blood flow was typically three-dimensional asymmetrical distribution. And with tapered angles increasing, the pressure difference in the vessel decreased, and the distribution nonuniformity of blood flow pressure weakened, the pressure gradient produced from the effect of gravity reduced 
gradually, yet the pressure distribution was invariably three-dimensional asymmetrical one.

Figures $\mathbf{3 b}(\mathbf{i})-\mathbf{3 b}(\mathbf{i i i})$ shows the pressure distribution of transverse section under different tapered angles with gravity considered $(G \neq 0)$. With tapered angles increasing from $0^{\circ}$ to $1^{\circ}$, the distribution of blood flow pressure tended gradually to be uniform and the effect intensity of gravity decreased gradually. This further demonstrated the conclusion drawn from the contour chart of the pressure distribution in the longitudinal section. In order to further identify the pure effect of gravity and the combined effect of gravity and tapered angles on
DBFP, the magnitude of the blood flow pressure along the symmetrical centerline and DBFP in the vessel were compared respectively under different tapered angles with or without gravity considered.

Figure 4 shows the comparison of the blood flow pressure distributions of longitudinal and transverse sections under different tapered angles with gravity considered or not. Whether gravity was considered or not, the distribution and magnitude of blood flow pressure in the vessel varied with tapered angles. With gravity considered, DBFP was always three-dimensional asymmetrical one at all three tapered angles.

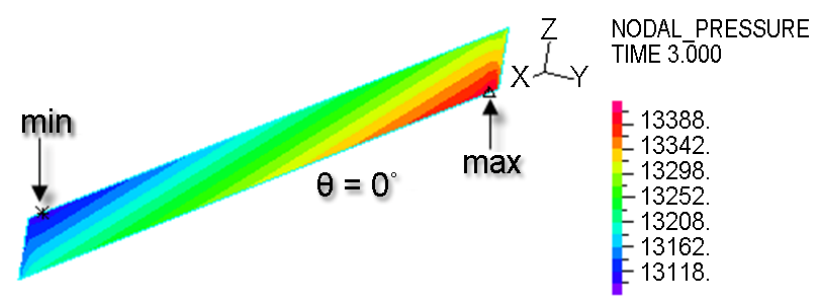

(i)

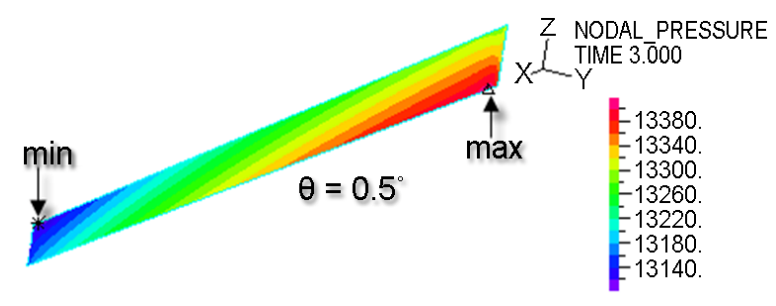

(ii)

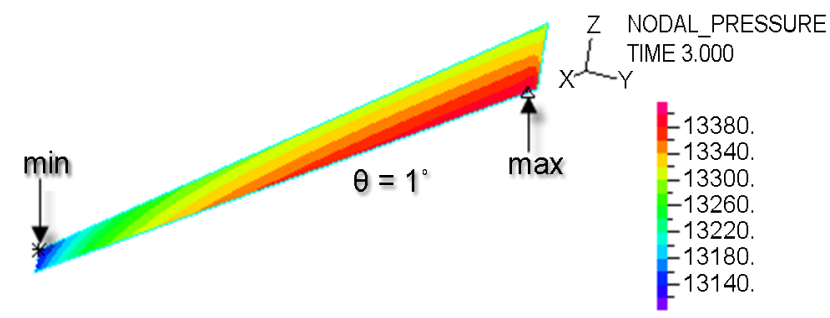

(iii)

(a)

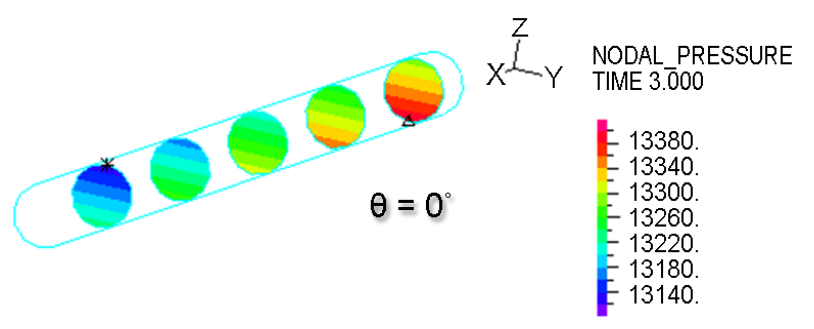

(i)

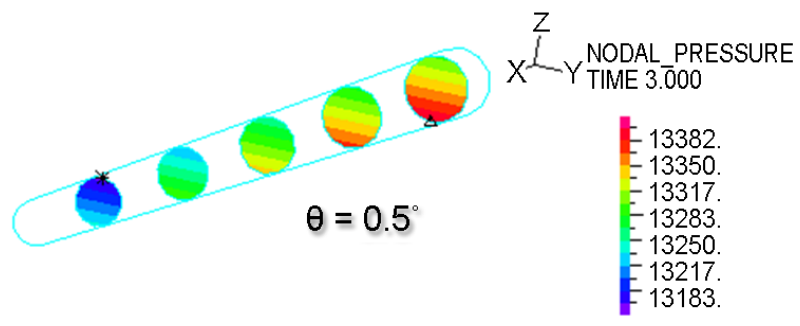

(ii)

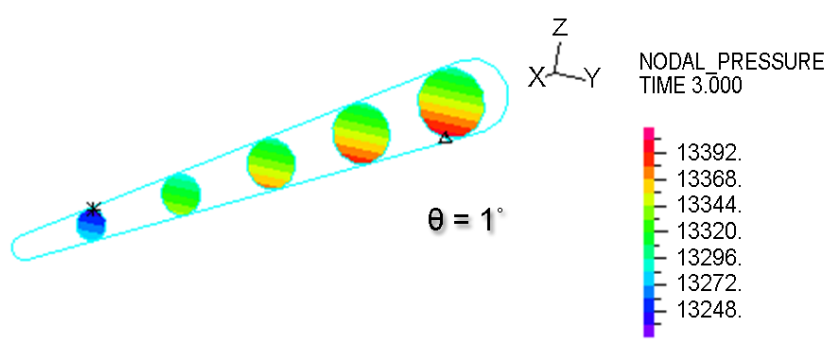

(iii)

(b)

Figure 3. Longitudinal and transverse section contour charts of distribution of blood flow pressure with different tapered angles ( $\Delta P=199.98 \mathrm{~Pa}, G \neq 0$, supine posture, $\theta$ is the tapered angle): (a) Longitudinal pressure distribution; (b) Transverse pressure distribution; (i) $\theta=0^{\circ}$, (ii) $\theta=0.5^{\circ}$, (iii) $\theta=1^{\circ}$. 

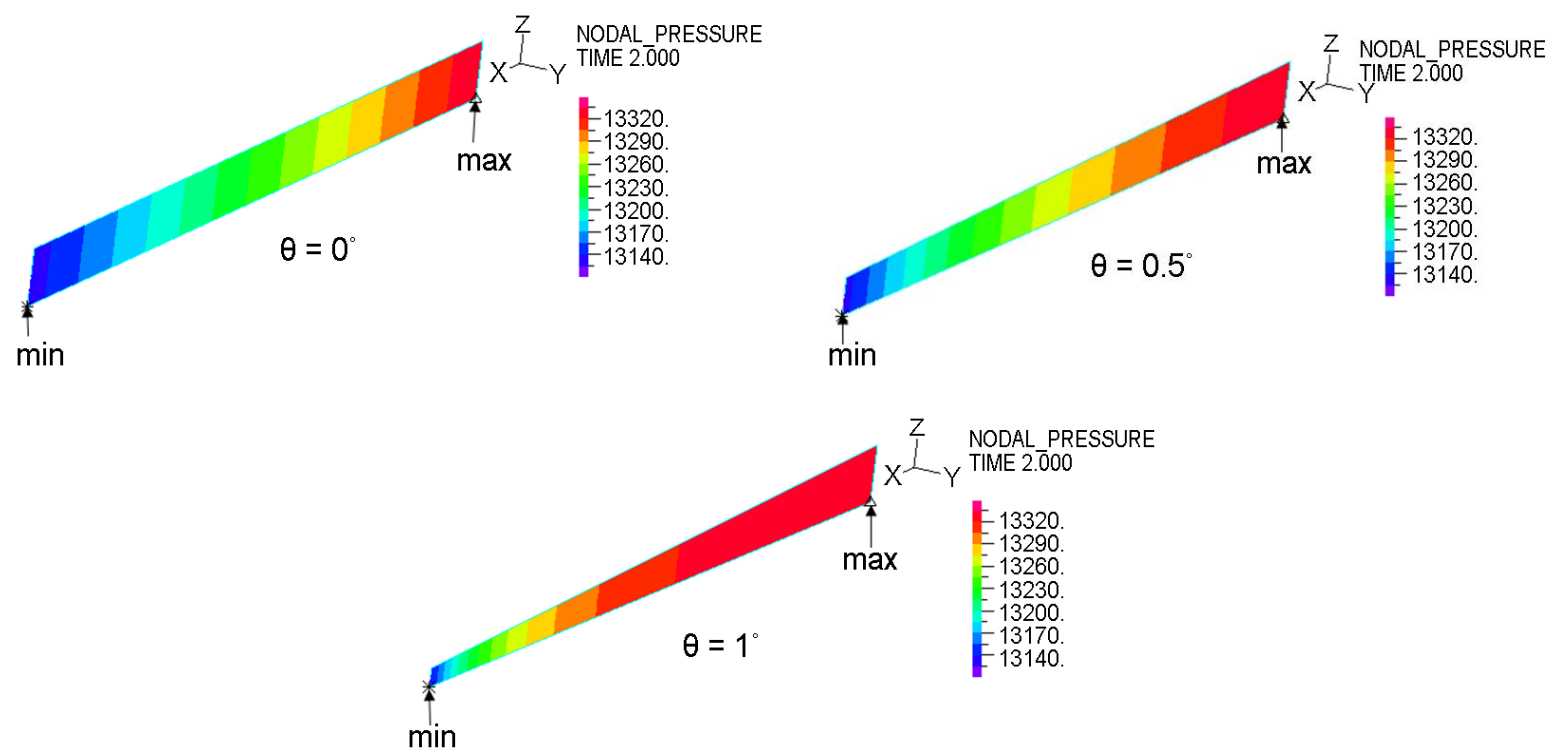

(i)
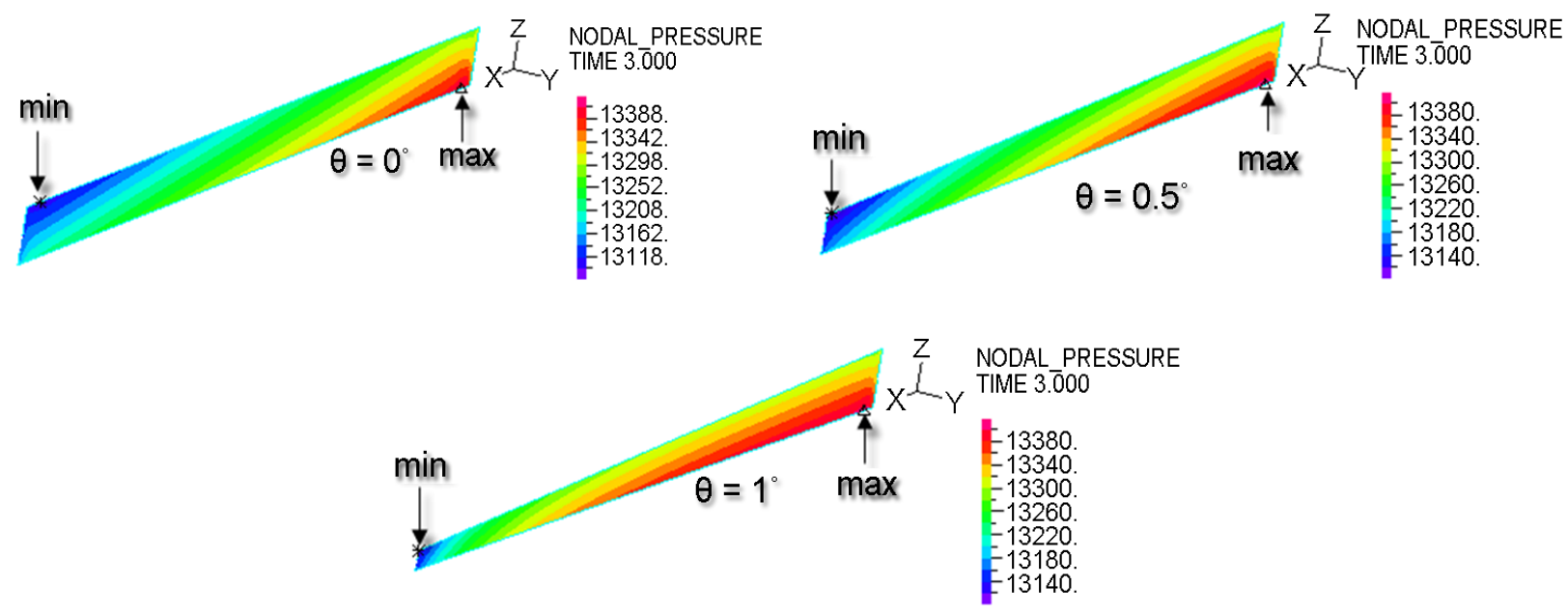

(ii)

(a)
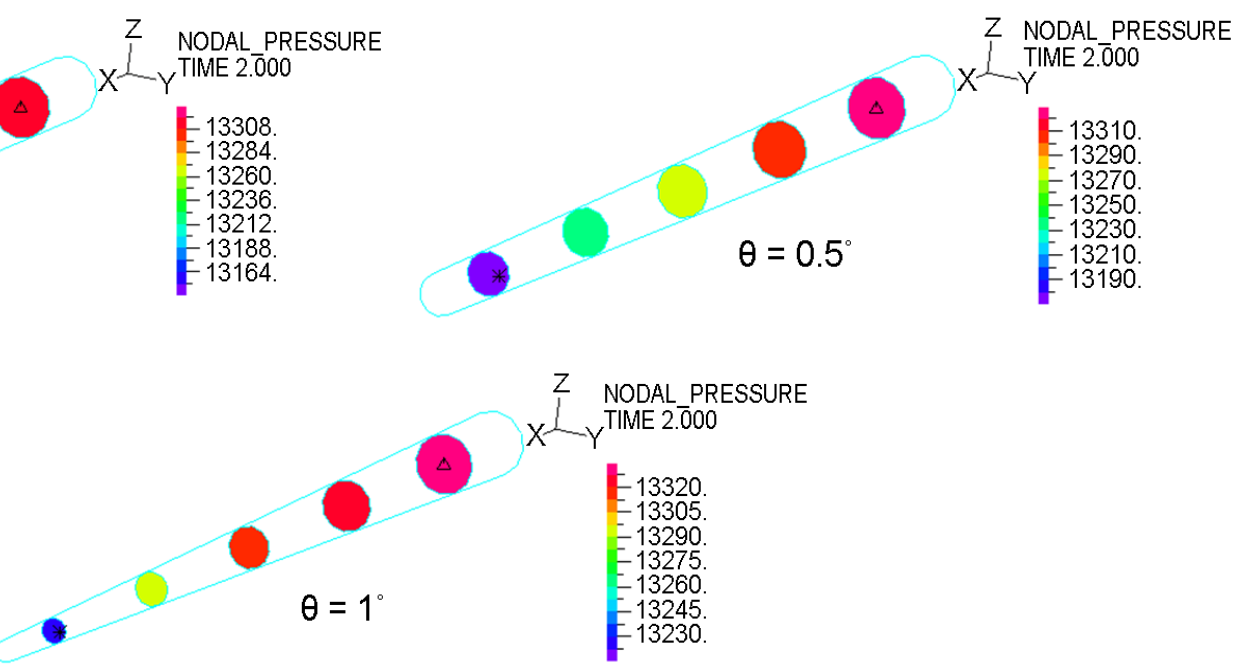

(i) 

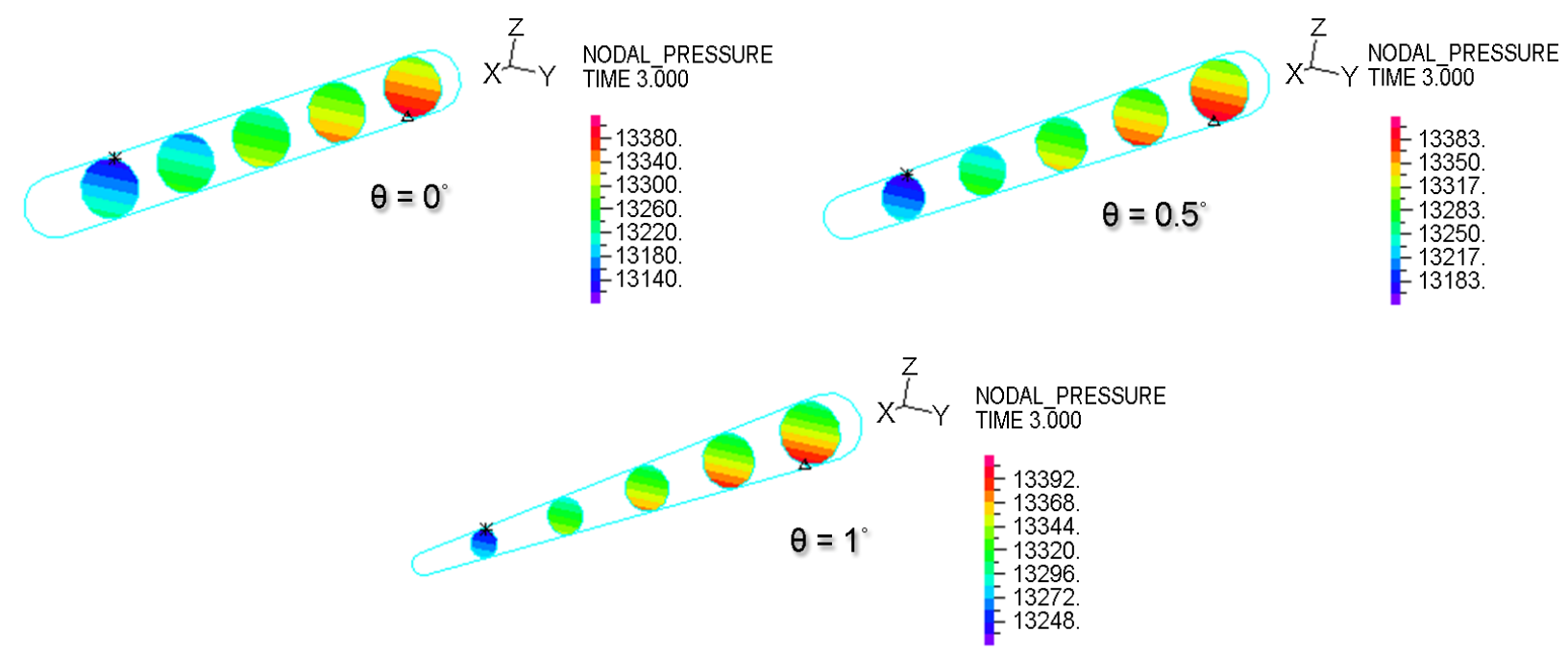

(ii)

(b)

Figure 4. Longitudinal and transverse section contour chart of distribution of blood flow pressure with different tapered angles ( $\triangle P=199.98 \mathrm{~Pa}, G \neq 0$ and $G=0$, supine posture, the tapered angle $\theta$ is $0^{\circ}, 0.5^{\circ}, 1^{\circ}$.): (a) Longitudinal pressure distribution; (i) $G=0$, (ii) $G \neq 0$. (b) Transverse pressure distribution; (i) $G=0$, (ii) $G \neq 0$.

At $1^{\circ}$ tapered angle, the effect intensity of gravity was $18.4 \%$ less than that at $0^{\circ}$ tapered angle as reference state, and $10.5 \%$ less at $0.5^{\circ}$ than that at $0^{\circ}$. With gravity neglected ( $G=0$ ), the blood flow pressure distribution was typically two-dimensional axisymmetrical one, and it was not affected by tapered angles. Accordingly, we concluded that the tapered angles affected only the magnitude of blood flow pressure and its position occurred, but not the dimension of DBFP. This was similar to Liu et al.'s results [22] which have reported that the tapered angles do not affect the flow type and distribution, and only change the value of the wall shear stress in the numerical simulation of the effect of the tapered angles and stenosis on the pulsating flow in an artery.

Figure 5 shows the blood flow pressure under different tapered angles along the axisymmetrical centerline of the vessel with gravity considered $(G \neq 0)$. From the inlet to outlet of the vessel, at $0^{\circ}$ tapered angle, the relationship between the blood flow pressure along the axisymmetrical centerline of the vessel and the distance from the vessel inlet visualized as a straight line, at $1^{\circ}$ tapered angle, the relationship figure became a curve, and at $0.5^{\circ}$ tapered angle, the curve was between the above two figure lines.

To further analyze the effect of gravity, the blood flow pressure figures at different tapered angles along the axisymmetrical centerline in the vessel with or without gravity considered were compared (shown in Figure 6).

The simulation indicated that the blood flow pressure change at different tapered angles along the axisymmetrical centerline of the vessel with gravity neglected ( $G=0$ ) was similar to that with gravity considered
( $G \neq 0$ ). With tapered angles increasing, the relationship between the blood flow pressure along axisymmetrical centerline of the vessel and the distance from the vessel inlet, developed from linear relation at $0^{\circ}$ tapered angle to non-linear relation at $1^{\circ}$ tapered angle. Also with tapered angles increasing, the nonlinearity was more evident. This means that the tapered effect of the vessel was one of the import factors leading to the nonlinearity of hemodynamic parameters and it was independent of gravity.

In addition, for the same tapered angle, the curves of blood flow pressure with gravity considered were all above those with gravity neglected. This indicated that the effect of gravity increased the magnitude of blood flow pressure, and the extent of increase in it varied with tapered angles. Ignoring the inlet-outlet effect, the blood flow pressure at $0^{\circ}$ tapered angle increased with the same amplitude from inlet to outlet. Whereas at $0.5^{\circ}$ and $1^{\circ}$ tapered angles, the increase rate of blood flow pressure gradually decreased. At the same position, the increase magnitude was the most at $0^{\circ}$ tapered angle, and at $0.5^{\circ}$, it took the second place, and the least at $1^{\circ}$ tapered angle. This suggested that gravity coupling with the tapered angles, affected the value of the blood flow pressure and its effect intensity. With tapered angles increasing, the effect intensity of gravity decreased. This was consistent with the conclusion drawn from the contour diagram of blood flow pressure distribution in longitudinal and transverse section.

This study suggest that without considering the tapered effect, taking cylindrical tube as the geometrical model in vessel study, there may be a big difference in 


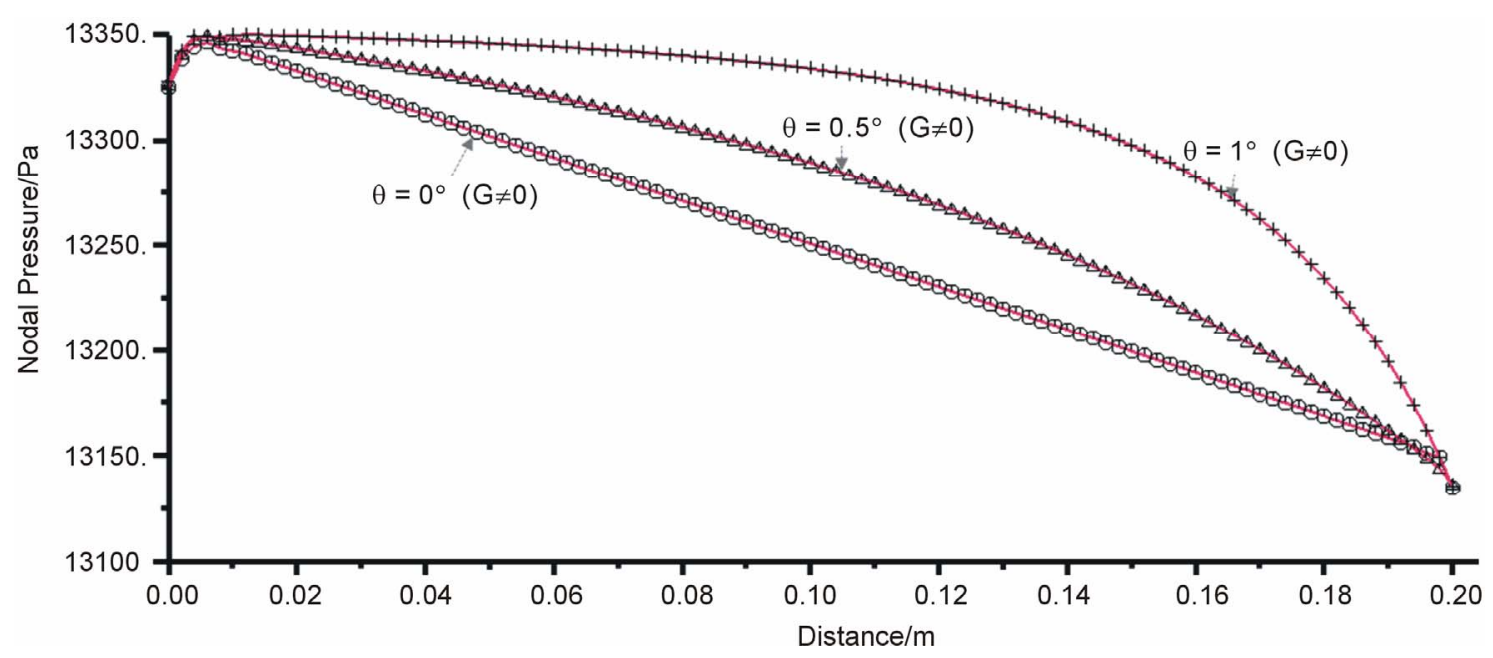

Figure 5. Blood flow pressure along the symmetrical centerline of the vessel with different tapered angles $(\Delta P=$ $199.98 \mathrm{~Pa}, G \neq 0$, supine posture, $\theta$ is the tapered angle): (a) $\theta=0^{\circ}$; (b) $\theta=0.5^{\circ}$; (c) $\theta=1^{\circ}$.

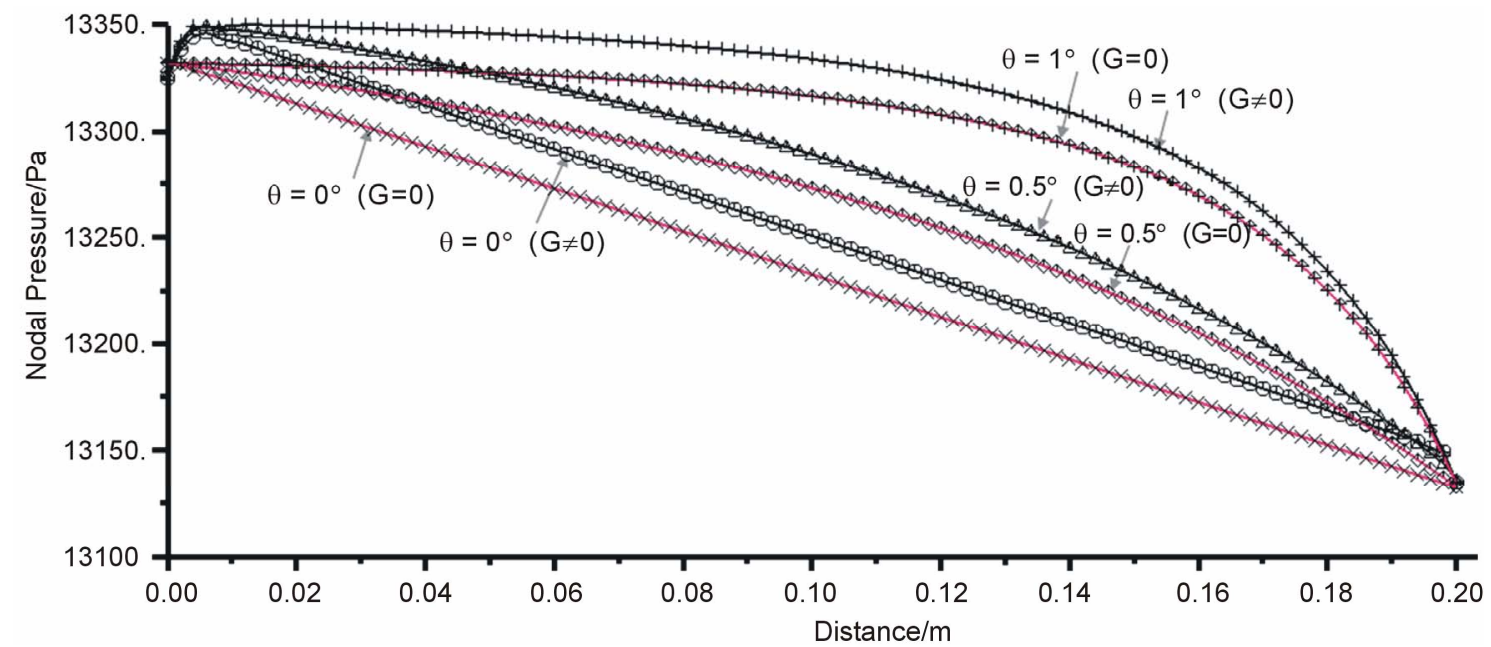

Figure 6. Curve of blood flow pressure at symmetrical centerline of the vessel with different tapered angles $(\Delta P=$ $199.98 \mathrm{~Pa}, G \neq 0$ and $G=0$, supine posture, $\theta$ is the tapered angle): (a) $\theta=0^{\circ}$; (b) $\theta=0.5^{\circ}$; (c) $\theta=1^{\circ}$.

the distribution and value of blood flow pressure between the obtained results and the real physiological situation. Therefore, considering the combined action of gravity and tapered angles will make the results in this study more close to the real physiology.

However, there are still some important factors not considered in the current study and could be added to improve the results: a) non-Newtonian flow properties and turbulent property of blood; b) patient-specific data; c) effect of vessel wall. Simple and ideal geometrical and physical model aids in reducing the computational cost and obtaining the results rapidly. For the present study, this assumption would not alter the total trend of DBFP with gravity and tapered angles, so it is easier to get the pure results about the effect of different tapered angles with gravity considered or not, which excludes the other action.

\section{CONCLUSION}

In conclusion, whether gravity is considered or not, the tapered effect is one of the important factors leading to nonlinearity in such hemodynamic parameters as blood flow pressure. The tapered angles, together with gravity, affected the magnitude of the blood flow pressure. Gravity, however, independently influenced the dimension of the DBFP, which had nothing to do with the tapered angles.

\section{ACKNOWLEDGEMENTS}

The authors would like to thank Prof. LIU Da'an of Institute of Geol-ogy and Geophysics, Chinese Academy of Sciences for providing us with the computational tool freely. We also thank Prof. Yang C. and Dr. Bai Rong for their helpful advice.

Also, this paper was supported by National Natural Scientific Foun- 
dation of China (No.81227001) and the National Science and Technology Support Program (No.2012BAI14B04).

\section{REFERENCES}

[1] Grigoriev, A.I., Kotovskaya, A.R. and Fomina, G.A. (2011) The human cardiovascular system during space flight. Acta Astronautica, 68, 1495-1500. http://dx.doi.org/10.1016/j.actaastro.2009.11.013

[2] Hughson, R.L., Yamamoto, Y., Maillet, A., Fortrat, J.O., Traon, A., Butler, G.C., Giiellr, A. and Gharib, C. (1994) Altered autonomic regulation of cardiac function during head-up tilt after 28-day head-down bed-rest with countermeasures. Clinical Physiology, 14, 291-304. http://dx.doi.org/10.1111/j.1475-097X.1994.tb00386.x

[3] Arbeille, P., Sigaudo, D., LeTraon, A.P., Herault, S., Porcher, M. and Gharib, C. (1998) Femoral to cerebral arterial blood flow redistribution and femoral vein distension during orthostatic tests after 4 days in the head-down tilt position or confinement. European Journal of Applied Physiology and Occupational Physiology, 78, 208-218. http://dx.doi.org/10.1007/s004210050409

[4] Hamilton, D.R., Sargsyan, A.E., Garcia, K., Ebert, D.J., Whitson, P.A., Feiveson, A.H., et al. (2012) Cardiac and vascular responses to thigh cuffs and respiratory maneuvers on crewmembers of the International Space Station. Journal of Applied Physiology, 112, 454-462. http://dx.doi.org/10.1152/japplphysiol.00557.2011

[5] Hall, P. (1974) Unsteady viscous flow in a pipe of slowly varying cross-section. Journal of Fluid Mechanics, 64, 209-226. http://dx.doi.org/10.1017/S0022112074002369

[6] Bakırtaş, I. and Demiray, H. (2005) Weakly non-linear waves in a tapered elastic tube filled with an inviscid fluid. International Journal of Non-Linear Mechanics, 40, 785-793. http://dx.doi.org/10.1016/j.ijnonlinmec.2004.03.003

[7] Sankar, D.S. and Hemalatha, K. (2007) Non-linear mathematical models for blood flow through tapered tubes. Applied Mathematics and Computation, 188, 567-582. http://dx.doi.org/10.1016/j.amc.2006.10.013

[8] Mandal, P.K. (2005) An unsteady analysis of non-Newtonian blood flow through tapered arteries with a stenosis. International Journal of Non-Linear Mechanics, 40, 151164. http://dx.doi.org/10.1016/j.ijnonlinmec.2004.07.007

[9] Nadeem, S. and Akbar, N.S. (2010) Simulation of the second grade fluid model for blood flow through a tapered artery with a stenosis. Chinese Physics Letters, 27, 068701-1-068701-4. http://dx.doi.org/10.1088/0256-307X/27/6/068701

[10] Nadeem, S. and Akbar, N.S. (2011) Power law fluid model for blood flow through a tapered artery with a stenosis. Applied Mathematics and Computation, 217, 7108-7116. http://dx.doi.org/10.1016/j.amc.2011.01.026
[11] Sundell, P.M. and Roach, M.R. (1998) The role of taper on the distribution of atherosclerosis in the human infrarenal aorta. Atherosclerosis, 139, 123-129. http://dx.doi.org/10.1016/S0021-9150(98)00068-9

[12] Melchior, F.M., Srinivasan, R.S., Thullier, P.H. and Clere, J.M. (1994) Simulation of cardiovascular response to lower body negative pressure from 0 to $40 \mathrm{mmHg}$. Journal of Applied Physiology, 77, 630-640.

[13] Olufsen, M.S., Ottesen, J.T., Tran, H.T., Ellwein, L.M. and Novak, V. (2005) Blood pressure and blood flow variation during postural change from sitting to standing: Model development and validation. Journal of Applied Physics, 99, 1523-1537.

http://dx.doi.org/10.1152/japplphysiol.00177.2005

[14] Mu, W.Y., Yu, G., Zhuang, F.Y. and An, G.M. (2009) Mathematical model of hemodynamics with posture. Journal of Medical Biomechanics, 23, 441-446.

[15] Caro, C.G., Pedley, T.J., Schroter, R.C. and Seed, W.A. (1978) "Blood" and "The systemic arteries". In: The mechanics of the circulation, Oxford, New York, 4-30.

[16] Fung, Y.C. (c1981) The flow properties of blood. In: Biomechanics: Mechanical properties of living tissues, Springer-Verlag, New York, 62-98.

[17] Taylor, C.A. and Draney, M.T. (2004) Experimental and computational methods in cardiovascular fluid mechanics. Annual Review of Fluid Mechanics, 36, 197-231. http://dx.doi.org/10.1146/annurev.fluid.36.050802.12194 4

[18] Kwak, D., Kiris, C. and Kim, C.S. (2005) Computational challenges of viscous incompressible flows. Computers \& Fluids, 34, 283-299. http://dx.doi.org/10.1016/j.compfluid.2004.05.008

[19] Matthys, K.S., Alastruey, J., Peiró J., Khir A.W., Segers P., Verdonck P.R., Parker, K.H. and Sherwin, S.J. (2007) Pulse wave propagation in a model human arterial network: Assessment of 1-D numerical simulations against in vitro measurements. Journal of Biomechanics, 40, 3476-3486. http://dx.doi.org/10.1016/j.jbiomech.2007.05.027

[20] Kaazempur-Mofrad, M.R., Bathe, M., Karcher, H., Younis, H.F., Seong, H.C., Shim, E.B., et al. (2003) Role of simulation in understanding biological systems. Computers \& Structures, 81, 715-726. http://dx.doi.org/10.1016/S0045-7949(02)00481-9

[21] Tang, D., Yang, C., Kobayashi, S., Zheng, J. and Vito, R.P. (2003) Effect of stenosis asymmetry on blood flow and artery compression: a three-dimensional fluid-structure interaction model. Annals of Biomedical Engineering, 31, 1182-1193. http://dx.doi.org/10.1114/1.1615577

[22] Liu, G.T., Wang, X.J., Ai, B.Q. and Liu, L.G. (2004) Numerical study of pulsating flow through a tapered artery with stenosis. Chinese Journal of Physics, 42, 401409 . 